\title{
Relative Depth Effects on Corrugated Culvert Roughness
}

\author{
Jonathan Scott Toews, Shawn Paul Clark* \\ Civil Engineering, University of Manitoba, Winnipeg, Canada \\ Email: ${ }^{*}$ clarks@cc.umanitoba.ca
}

Received August 20, 2012; revised September 18, 2012; accepted October 20, 2012

\begin{abstract}
Fish passage is important to the overall health of an ecosystem. Therefore, it is important to be able to accurately predict flow conditions within a stream crossing for high and low flow periods. This paper evaluates the effect of relative water depth on the hydraulic roughness of culverts at low discharge. A $21 \mathrm{~m}$ long, $0.8 \mathrm{~m}$ diameter corrugated steel pipe with $0.068 \times 0.013 \mathrm{~m}$ annular corrugations was used. For relative depths below 0.5 , Manning's $n$ was found to increase with decreasing relative depth. An equation was developed to predict relative depths below 0.5 within a corrugated steel pipe based on the corrugation height, slope and culvert diameter. While Manning's equation does perform reasonably well, the percent difference from the measured to predicted water levels warrants the use of an additional prediction method at low flows.
\end{abstract}

Keywords: Culverts; Fish Passage; Low Flows; Roughness; Manning's Equation

\section{Introduction}

The process of fish migration and movement within rivers and streams is important for the health of the local ecosystem. When fish have the opportunity to move freely in any habitat they desire, they will generally flourish. The construction of culverts may become a barrier to fish, which may have a harmful effect on fish passage. High water velocities commonly present a barrier to fish passage, typically corresponding to peak flows from spring run-off. At low flows, however, shallow water depths within a culvert may become a barrier to fish passage, thus requiring a minimum depth within a culvert [1]. During the spawning period it is recommended by the Manitoba Stream Crossing Guidelines that the depth should not exceed half the diameter of the pipe [2]. This leads to the motivation of this paper, which looks into the effect of small relative depths $(h / D \leq 0.5)$ on the Manning's $n$ value within a culvert.

\section{Literature Review}

The majority of previous work on partially full circular culverts did not involve evaluation of the effect of relative depth on Manning's $n$. Straub and Morris [3] completed tests on corrugated metal pipe (CMP) culverts with three diameters of $0.46,0.61$, and $0.91 \mathrm{~m}$. The corrugation size used for these tests was $0.068 \times 0.013 \mathrm{~m}$, with a slope of $0.20 \%$ and a length of $65.8 \mathrm{~m}$. A total of 36 tests were conducted for all three diameters with rela-

${ }^{*}$ Corresponding author. tive depths ranging between 0.30 and 0.90 . Sterling [4] completed tests in smooth open channels of circular cross-section to determine the characteristics of fully developed turbulent flow. The pipe had a diameter of $0.24 \mathrm{~m}$ in a $22 \mathrm{~m}$ long tilting flume. Relative depths for their tests ranged from 0.10 to 0.89 . Results showed that Manning's $n$ tended to increase with decreasing relative depth. Ead et al. [5] completed tests on a $0.622 \mathrm{~m}$ diameter CMP culvert with $0.068 \times 0.013 \mathrm{~m}$ corrugations at slopes of $0.55 \%, 1.14 \%$ and $2.55 \%$. Relative depths ranged between 0.15 and 0.55 .

Kansas Department of Transportation [6] completed research on helical CMP culverts with $0.068 \times 0.013 \mathrm{~m}$ corrugations for three diameters of $0.46,0.38$ and $0.30 \mathrm{~m}$. These culverts were each tested at a single slope which was $0.39 \%, 0.85 \%$ and $0.68 \%$ respectively for each diameter. The range of relative depths observed within this study was 0.29 to 0.90 . From this data it is also noted that Manning's $n$ increases as the depth decreases within a CMP culvert. Abbs et al. [7] completed work on a $0.5 \mathrm{~m}$ diameter CMP culvert with $0.068 \times 0.013 \mathrm{~mm}$ corrugations set on a $0.72 \%$ slope. For the purpose of the current paper, results of only two tests have been used.

Mangin [8] compiled numerous data sets to develop an equation that could predict the water depth within a circular channel for open channel flow without the need to predict Manning's $n$. Dimensional analysis was performed to determine the most appropriate variables to predict the relative depth, resulting in Equation (1): 


$$
\frac{h}{D}=0.32\left[\left(\frac{\frac{Q}{\sqrt{g D^{5}}}}{\sqrt{S}}\right)\left(\frac{K_{s}}{D}\right)^{1 / 6}+0.64\right]
$$

where $h$ is the water depth, $D$ is the culvert diameter, $Q$ is the discharge, $g$ is gravity, $S$ is the slope, and $K_{S}$ is the roughness height. However, this equation was developed for $h / D>0.2$.

\section{Experimental Apparatus and Procedures}

The apparatus used at the University of Manitoba's Hydraulics Research \& Testing Facility (HRTF) consisted of a $21 \mathrm{~m}$ long, $0.8 \mathrm{~m}$ diameter CMP culvert with $0.068 \times$ $0.013 \mathrm{~m}$ annular corrugations. The culvert was supported on a series of adjustable yokes to allow slope adjustment. A headwater box along with flow straighteners were used to provide sufficient length for the flow to develop in the streamwise direction. A tailwater box with a flap gate was used to control the tailwater level within the model. Uniform depth was forced throughout the length of the culvert to ensure that normal depth was observed. The water surface profiles were measured using a series of manometer tubes along the length of the culvert. The water depth was recorded from the manometers as well as a point gauge with a vernier scale to ensure accurate measurement of the flow depth. The flow rate was measaured using a MSR Magnum Standard Magmeter and a custom designed LabVIEW interface at discharges greater than $20 \mathrm{~L} / \mathrm{s}$, while the low flow rates were measured using a calibrated triangular sharp-crested weir. The procedure consisted of setting the desired discharge within the culvert followed by carefully adjusting the tailgate setting to achieve uniform depth. The discharge and water depth were then measured. Measured relative depths ranged from 0.03 to $0.67 \mathrm{~h} / \mathrm{D}$ for each slope tested $(0.04$, $0.14,0.27,0.49$ and $0.75 \%$ ).

\section{Results and Analysis}

The corrugation type, corrugation size, discharge, depth, diameter and culvert slope were extracted from the [3], [5], and [7] to compliment the data collected at the HRTF. This data was then used to calculate the Manning's $n$ value for the culvert at that depth and discharge. It was found that there was a significant increase in Manning's $n$ as the depth within the culvert decreased, which can be seen in Figure 1, where $n_{f}$ is used to denote Manning's $n$ for full pipe flow as determined by the Corrugated Steel Pipe Institute [9].

Figure 1 shows that the largest variation in Manning's $n$ occurs at relative depths below 0.5 . Therefore a set of equations were developed, using a least squares regression for the variation in Manning's $n$, which is shown below as

$$
n=\left\{\begin{array}{ll}
0.878 n_{f}(h / D)^{-0.175} & \text { for } h / D \leq 0.5 \\
n_{f} & \text { for } h / D>0.5
\end{array}\right\}
$$

By dividing the equation into two portions a slightly better fit was achieved than simply applying a power regression to the entire relationship, improving the $R^{2}$ from 0.58 to 0.62 . The proportionality plot in Figure 2 shows that Manning's Equation using a constant value for $\mathrm{n}$ gives good results over the entire range. However, using a varying Manning's $n$ slightly increases the correlation between the observed and predicted relative depths (Figure 3). This is better represented by Figure 4, which shows the percent difference between the predicted and observed data. There is significant improvement for relative depths below 0.2. Figure 5 shows the predicted results using the equation developed by Manning, 2010.

As seen it does not do a good job of predicting the flow depth below a relative depth of a 0.2. This led to the development of a new equation, using the same dimensionless parameters that were developed by Manning [8] using dimensional analysis. The dimensionless parameters $S$ and $Q / \sqrt{g D^{5}}$ were then plotted against the relative depth to determine the exponential relationship between them. The exponential relationship for $K_{s} / D$ could not be determined in a similar fashion since the tests were not conducted at the same slopes between each report. Therefore the exponential relationship for $K_{\mathrm{s}} / D$

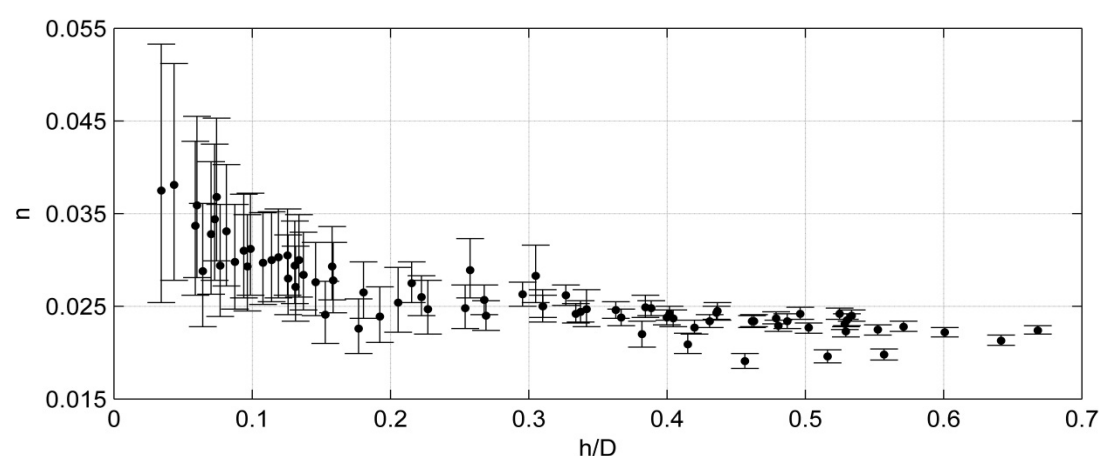

Figure 1. Normalized Manning's $n$ versus relative depth for data collected at the HRTF. 


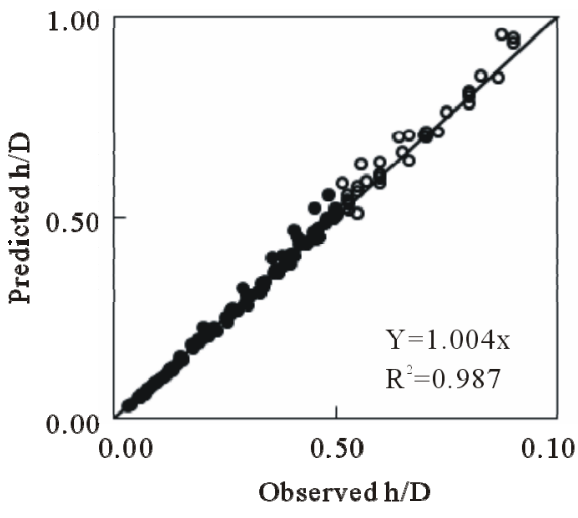

Figure 2. Proportionality plot of predicted vs observed h/D using a constant Manning's $n$.

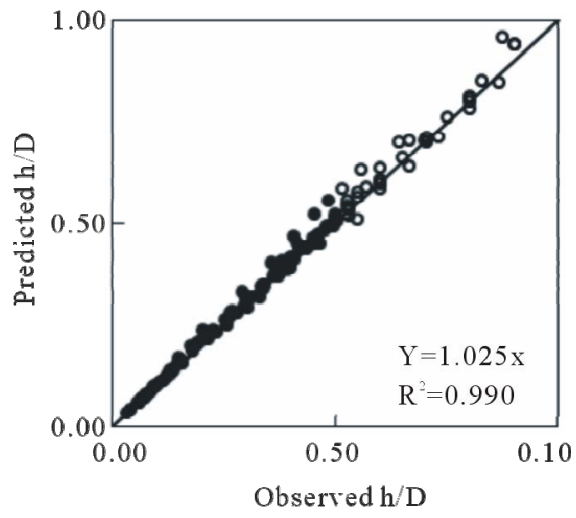

Figure 3. Proportionality plot of predicted vs observed h/D using a varying Manning's $n$.

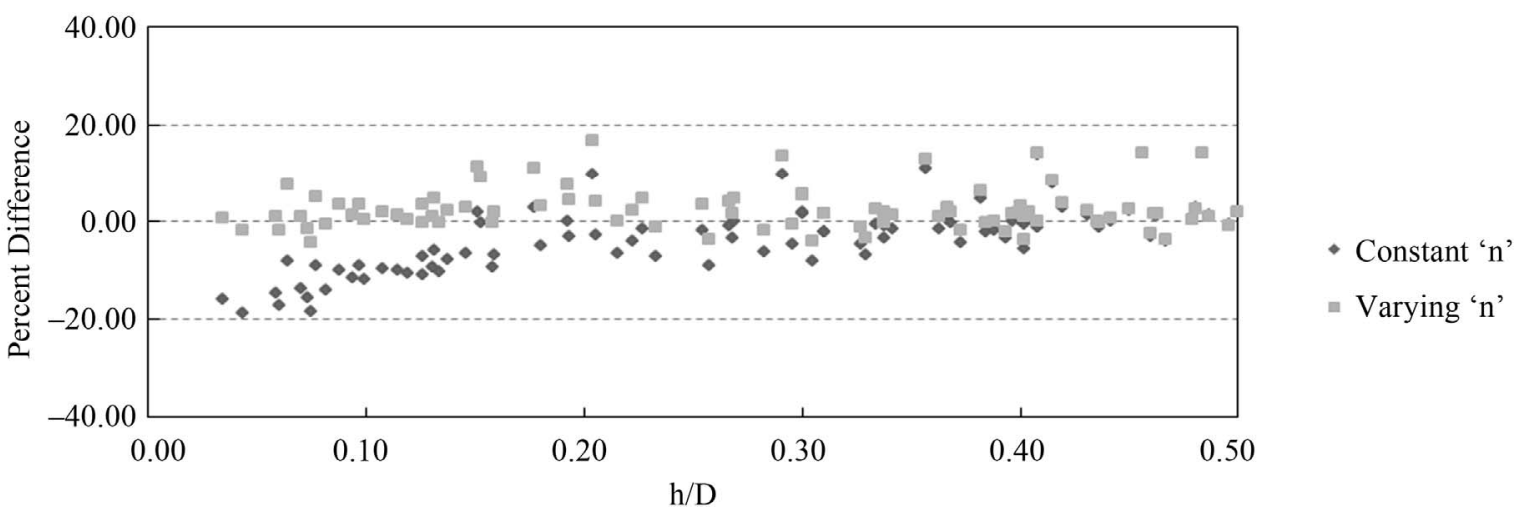

Figure 4. Comparison of predicted and measured relative depth for Manning's Equation using a constant and varying $n$.

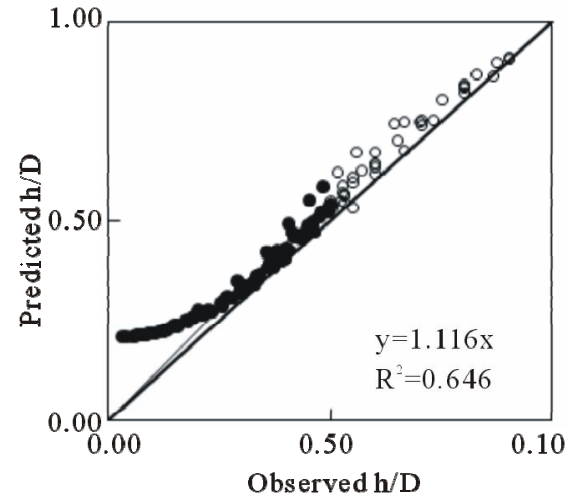

Figure 5. Proportionality plot for Manning's Equation.

and trend multiplier were then optimized to minimize the total error between predicted and observed relative depths. The final form of the equation is

$$
\frac{h}{D}=0.641\left(\frac{Q}{\sqrt{g D^{5}}}\right)^{0.463} S^{-0.247}\left(\frac{K_{s}}{D}\right)^{0.169}
$$

As seen in Figures 6 and 7, this equation accurately predicts relative depths below 0.5 . However the model error tends to increase as the relative depth increases past this threshold. This was determined not to be an issue

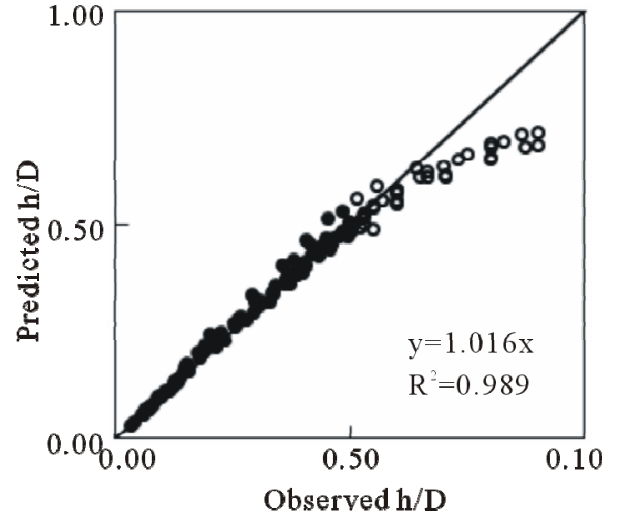

Figure 6. Proportionality plot for Equation (3).

since Manning's Equation is accurate in this region.

\section{Conclusions}

Results indicate that Manning's Equation using a constant $n$ value does a reasonable job of predicting the uniform depth within CMP culverts over a wide range of water depths despite the fact that the roughness coefficient has been shown to increase with decreasing $h / D$. At very low water depths $(h / D<0.15)$ Equation $(3)$ performs better than Manning's Equation, and may be a 


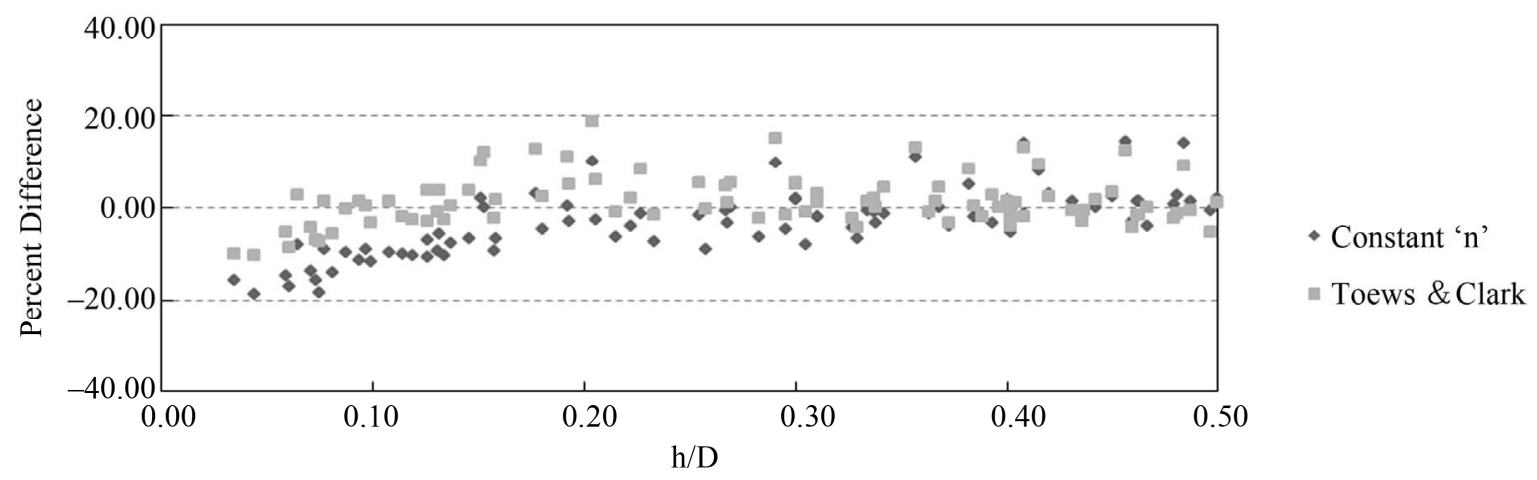

Figure 7. Comparison of predicted and measured relative depth for Manning's Equation and Equation (3).

more accurate means of estimating minimum flow depths for fish passage at low discharge. At these very shallow flows the resistance from the corrugations seem to act as form drag, rather than merely a uniform skin friction.

The difficulty with Equation (3) is that its accuracy has not been verified over a significant range of corrugation heights and culvert diameters. The advantage of using this equation is that a varying roughness coefficient does not need to be developed. It also has been shown to be accurate up to the mid-depth of the culvert, which corresponds to the upper depth limit in the Manitoba Stream Crossing Guidelines for culverts. Some recommended future works include testing other corrugation sizes at similar slopes to determine the variation of Manning's $n$ for different CMP culvert types. This would also allow for a better determination of the relative depths reliance on the relative roughness.

\section{Acknowledgements}

The authors wish to thank the NSERC, Manitoba Hydro, Manitoba Infrastructure and Transportation, and the Corrugated Steel Pipe Institute of Canada for their support.

\section{REFERENCES}

[1] R. H. Hotchkiss and C. M. Frei, "Design for Fish Passage at Roadway-Stream Crossings: Synthesis Report," US Department of Transportation Federal Highway Administrations, 2007.

http://www.fhwa.dot.gov/engineering/hydraulics/pubs/07 033/07033.pdf
[2] Fisheries and Oceans Canada, "Manitoba Stream Crossing Guidelines for the Protection of Fish and Fish Habitat," Manitoba Natural Resources, 1996.

[3] L. G. Straub and H. M. Morris, "Hydraulic Tests on Corrugated Metal Culvert Pipes," University of Minnesota, 1950.

http://conservancy.umn.edu/bitstream/107915/1/tp_005b. pdf

[4] M. Sterling, "A Study of Boundary Shear Stress, Flow Resistance and the Free Overfall in Open Channels with a Circular Cross-Section," PhD Thesis, University of Birmingham, Birmingham, 1998.

[5] S. A. Ead, N. Rajaratnam, C. Katopodis and F. Ade, "Turbulent Open-Channel Flow in Circular Corrugated Culverts," Journal of Hydraulic Engineering, Vol. 126, No. 10, 2000, pp. 750-757.

[6] B. M. McEnroe and T. R. Malone, "Hydraulic Resistance of Small-Diameter Helically Corrugated Metal Pipe," Kansas Department of Transportation, 2008. http://www.ksdot.org/PublicLib/doccontent.dll?LibraryN ame $=$ PulicDocs ${ }^{\wedge} \mathrm{dt} 00 \mathrm{mx} 38 \&$ System Type $=2 \&$ LogonId $=6$ b54f3f0243eb4a610c004fb9e94f3e2\&DocId=003768569

[7] T. J. Abbs, J. A. Kells and C. Katopodis, "A Model Study of the Hydraulics Related to Fish Passage through Backwatered Culverts," Proceedings of the 18th CSCE Hydro Technical Conference, Winnipeg, 22-24 August 2007.

[8] S. F. Mangin, "Development of an Equation Independent of Manning's Coefficient $n$ for Depth Predictions in Partially-Filled Circular Culverts," MSc Thesis, Youngstown State University, Youngstown, 2010.

[9] Corrugated Steel Pipe Institute, "Handbook of Steel Drainage \& Highway Construction," 2nd Canadian Edition, American Iron and Steel Institute, 2007. 